Whether the pathology within and around the nerve after external compresson is due to mechanical deformation or to ischaemia or to a combination of both is uncentain. According to Sunderland, ${ }^{10}$ "the available evidence points to a local disturbance of axoplasmal structure whch is confined to the damaged segment, and/or a slowing or arrest of 'the centrifugal flow inside the axon of substances or factors vital for the maintenance of axonal integrity.' Providing the causative agent ceases to act before the critical point is reached at which axonal disintegration sets in, the changes responsible for the block are, whatever their nature, fully reversible and function is rapidly and completely restored." Unfortunately, the "critical point" cannot be obvious clinically, and the only safe approach is to avoid pressure altogether over this vulnerable segment of nerve. Damaged nerve fibres are more sensitive to ischaemia than normal fibres ${ }^{11} 12$ and it is important, therefore, to watch for the presence of the cubital tunnel external compression syndrome in hospital practice; the patient should be informed whenever the syndrome is present and advised that all forms of pressure over the cubital tunnel must be prevented, as should prolonged periods of severe elbow flexion. Adequate follow-up by the clinician is necessary and the prognosis should be guarded. From our experience in this series normal sensation never returns and such a significant improvement of severe muscle weakness as occurred in case 10 is unusual.

The place of surgical treatment in the cubital tunnel external compression syndrome cannot at present be well defined. The amount of force and length of time it has been applied probably determine whether only the superficial epineurium is affected or whether the interfunicular connective tissue, the perineurium, and, finally, the intrafunicular tissue is involved. Even when a nerve is superficially involved it may be surrounded or even buried in scar tissue. External neurolysis is sometimes performed in the belief that scar tissue is blocking conduction or hindering regeneration, as in cases $1,2,8,9$, and 11. Surgical intervention halted the progression in cases 2,9 , and 11, while there was limited reversal of the palsy in cases 1 and 8 . The indication for internal neurolysis is even more difficult to assess. It was performed by saline injection in cases 1,8 , and 9 because of intraneural thickening. Sunderland ${ }^{13}$ believes that interfunicular injection of saline is no substitute for careful intraneural exploration, and if the latter is contraindicated because of dense scarring intraneural injection of fluid will anyway be ineffective. Never- theless, injection of saline may indicate the amount of intraneural fibrosis and so be helpful in prognosis.

Surgical exploration is indicated when there is progressive deterioration over several months. After neurolysis the nerve can be left free with the arcuate ligament sewn deep to it, the nerve can be transposed anteriorly ${ }^{15}$ or the medial epicondyle and adjacent supracondylar ridge removed. ${ }^{16}$ Anterior transposition of a dislocating, hypermobile nerve which is the subject of neuropathy is mandatory.

Early recognition of the cubital tunnel external compression syndrome and a fully-informed patient aware of the danger of subsequent external pressure over the cubital tunnel set the stage for a more favourable outcome. Positions on the operating table, in bed, or in the armchair that put the cubital tunnel at risk from external pressure should be avoided and active elbow movement encouraged in bedridden patients.

It is a pleasure to acknowledge the help and encouragement of colleagues in different specialties and from several hospitals, and particularly so for providing many cases, not all of which are included in the present series.

Requests for reprints should be addressed to: T. G. Wadsworth, Department of Orthopaedic Surgery, Hackney Hospital, Homerton High Street, London E9 6BE, England, or to J. R. Williams, Department of Neurosurgery, Blodgett Memorial Hospital, Grand Rapids, Michigan 49506, U.S.A.

\section{References}

1 Wadsworth, T. G., Clinical Orthopaedics and Related Research, 1972, 85,

${ }^{2}$ Mitchell, S. W., Injuries of Nerves and their Consequences, V, 82. Philadelphia, Lippincott, 1872.

3 Skillern, P. G., jun., Surgical Clinics of North America, 1922, 2, 251.

4 Gurdjian, E. S., fournal of the American Medical Association, 1931, 96, 944. 5 Dhunér, K.-G., Anesthesiology, 1950, 11, 289

- Carr, J. A., British Medical fournal, 1957, 2, 1415

McGowan, A. J., Fournal of Bone and foint Surgery, 1950, 32B, 293.

Gowers, W. R., A Manual of Diseases of the Nervous System, 2nd edn. vol. 1, London, Churchill, 1892.

- Vanderpool, D. W., Chalmers, J., Lamb, D. W., and Whiston, T. B., fournal of Bone and foint Surgery, 1968, 50B, 792

10 Sunderland, S., Nerves and Nerve Injuries, 1968, 6, 70

11 Gilliatt, R. W., and Wilson, T. G., fournal of Neurology, Neurosurgery and Psychiatry, 1954, 17, 104 12 Fullerton, P. M., fournal of Neurology, Neurosurgery and Psychiatry,

13 Sunderland, S., Nerves and Nerve Injuries, 1968, 44, 558.

14 Osborne, G. V., The Hand, 1970, 2, 10.

15 Adson, A. W., Minnesota Medicine, 1918, 1, 455

16 King, T., and Morgan, F. P., Australian and New Zealand fournal of Surgery, 1950, 20, 33

17 Sunderland, S., Brain, 1945, 68, 243.

\title{
Cryodestruction of Haemorrhoids
}

\author{
K. LLOYD WILLIAMS, I. U. HAQ， B. ELEM
}

British Medical fournal, 1973, 1, 666-668

\section{Summary}

Thirty-seven cases of second and third degree haemorrhoids have been treated by cryosurgery. Although the number of cases treated is small and the follow-up is short, we are greatly encouraged by the early excellent results. It is a simple and

\footnotetext{
Department of Measurement and Clinical Research, St. Martin's Hospital, Bath, Somerset

K. LLOYD WILLIAMS, M.D., M.CHIR., Consultant Surgeon

I. U. HAQ, B.SC., F.R.C.S., Research Registrar

B. ELEM, F.R.C.S., Research Registrar (Prolo
Urology, Southmead Hospital, Bristol)
}

effective procedure with minimal complications, and it is especially recommended for those patients who are medically unfit for general anaesthesia. The rapidity of this procedure combined with the painless operative and postoperative course enables the patient to leave hospital the next day. More cases with long-term follow-up are needed before adequate evaluation of this form of treatment can be made.

\section{Introduction}

During a clinical trial of cryosurgery for advanced and recurrent cancers of the skin (to be reported) an inoperable carcinoma of the anal canal and a perineal recurrence after abdominoperineal resection were treated. We were impressed 
by the painlessness of the procedure and the absence of secondary infection and haemorrhage, and thought it feasible to try the effect of cryodestruction on third degree haemorrhoids. Initially we limited our attempts to patients with third degree haemorrhoids who were medically unsuitable for general anaesthesia. Later in the series we included patients with second and third degree haemorrhoids of normal operative risk.

\section{Patients and Methods}

Out of a series of 37 patients with second or third degree haemorrhoids, 25 have been followed up for six months or more, the maximum follow-up period being 20 months. Of these 25 patients, who form the basis of this preliminary report, 14 were women and 11 men (age range 35-89, average $52 \cdot 28$ years).

All had preoperative bleeding, and $80 \%$ had preoperative discharge as well as bleeding. All had prolapse of the haemorrhoids, permanent in $60 \%$ and intermittent in $40 \%$. Altogether, $64 \%$ complained of irritation and $40 \%$ had pain. In all these patients the anal canal admitted two fingers easily on rectal examination.

All patients had preliminary protoscopy and sigmoidoscopy and, where indicated, a barium enema examination. All were admitted to hospital, but no premedication or preoperative preparation other than a full explanation of the procedure was necessary. If anxious on arrival in the theatre, the patient was given an intravenous injection of $5-10 \mathrm{mg}$ of diazepam, the dosage being adjusted according to age and physical condition. The patient was asked to lie in the left lateral position, and the right buttock was held up by the attending nurse. In this position the haemorrhoids became more apparent, and a preoperative photograph was taken. In cases with intermittent prolapse, whose haemorrhoids were not prolapsing adequately at this time, a little bearing down force by the patient, aided with digital traction by the surgeon, brought the haemorrhoids adequately down to the anal verge. Freezing of the haemorrhoids was then begun. The surgeon wore two pairs of surgical gloves to protect the fingers from freezing. The fingers, or a plastic vaginal speculum, or a modified plastic proctoscope were used to isolate one primary haemorrhoid plexus at a time. K-Y jelly was used to achieve good thermal contact between the cryoprobe and the haemorrhoid. Three different cryoprobes were used, and the period of freezing varied according to the cooling power of the probe. When a probe was applied to the haemorrhoid it first stuck to the tissue, which then became white and solid, the desired area of cryodestruction being judged by the area of solid, frozen tissue. With a liquid nitrogen probe at $-180^{\circ} \mathrm{C}$, or a liquid nitrous oxide probe at $-80^{\circ} \mathrm{C}$, the application time was about two minutes per haemorrhoidal area. With a gaseous nitrous oxide at $-70^{\circ} \mathrm{C}$, about three to three and a half minutes were necessary. Obviously the greater the vascularity of the haemorrhoid the greater the cooling power required to freeze it. Therefore the liquid nitrogen probe proved most effective for large haemorrhoids. When an adequate area of tissue had been frozen the probe was switched off, rewarmed, and detached from the haemorrhoid, each plexus being treated in the same way.

The patient was returned to the ward wearing an absorbent dressing such as a sanitary towel. No postoperative analgesic other than acetylsalicylic acid (Dispirin) or codeine was required in this series. A rectal examination was done as a routine next day. The length of postoperative stay in hospital was variable, some patients being retained for up to two weeks because of debility, home circumstances, or for observation of the natural history of the cryolesion. Ablebodied patients left on the first postoperative day. All were seen in outpatients at three weeks, six weeks, and thereafter at three and six months. The patient was warned that he would have a profuse rectal discharge for nine or 10 days, and would need frequent changes of dressing and saline baths. Bowel action was rarely painful, but he was asked to avoid constipation by taking bran or liquid paraffin.

\section{LOCAL EFFECT OF FREEZING}

Two to three hours after freezing the haemorrhoid becomes swollen and red (figs. 1 and 2). Within 72 hours pale spots appear on the surface and coalesce to form irregular pale

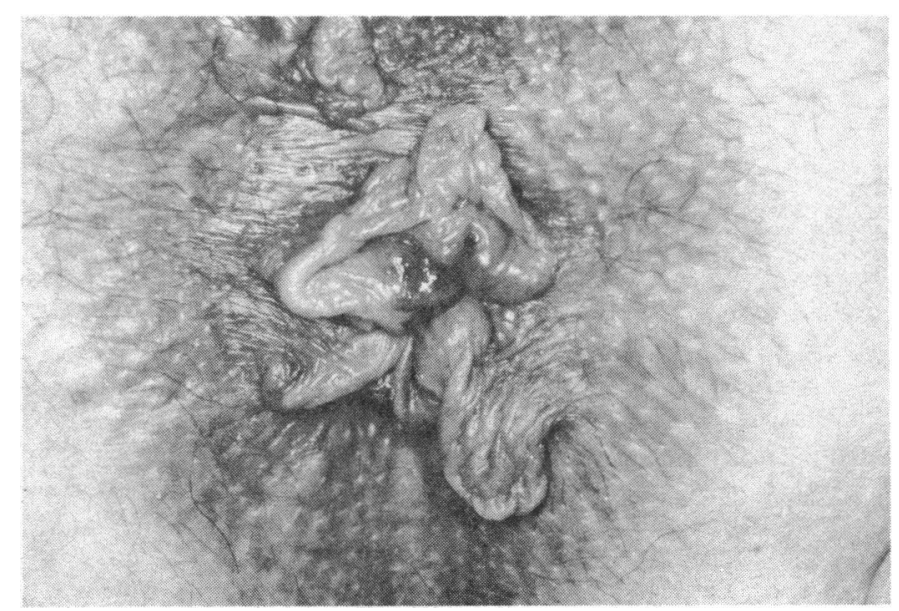

FIG. 1-Third degree haemorrhoids in 35-year-old woman before operation.

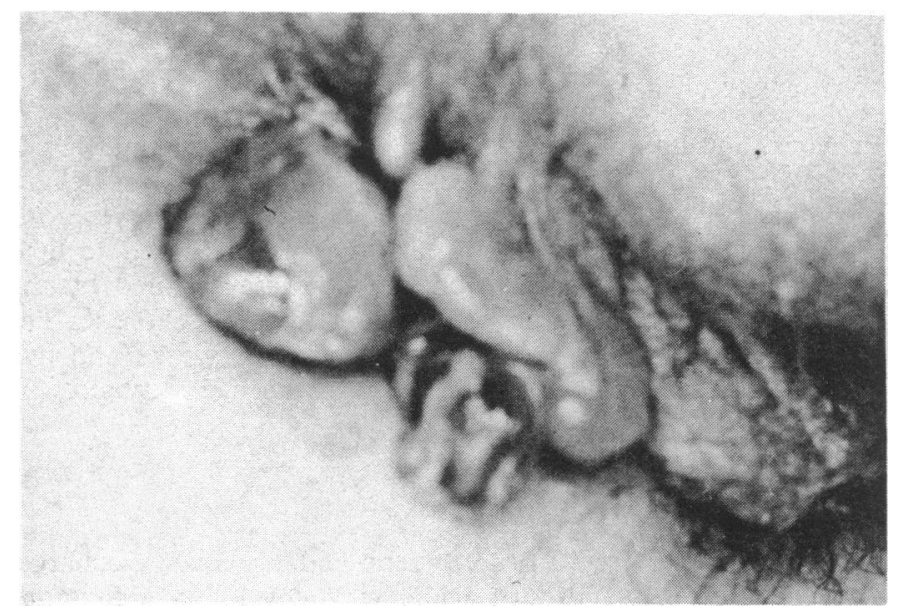

FIG. 2-Same patient two days later. Frozen haemorrhoids are swollen and congested.

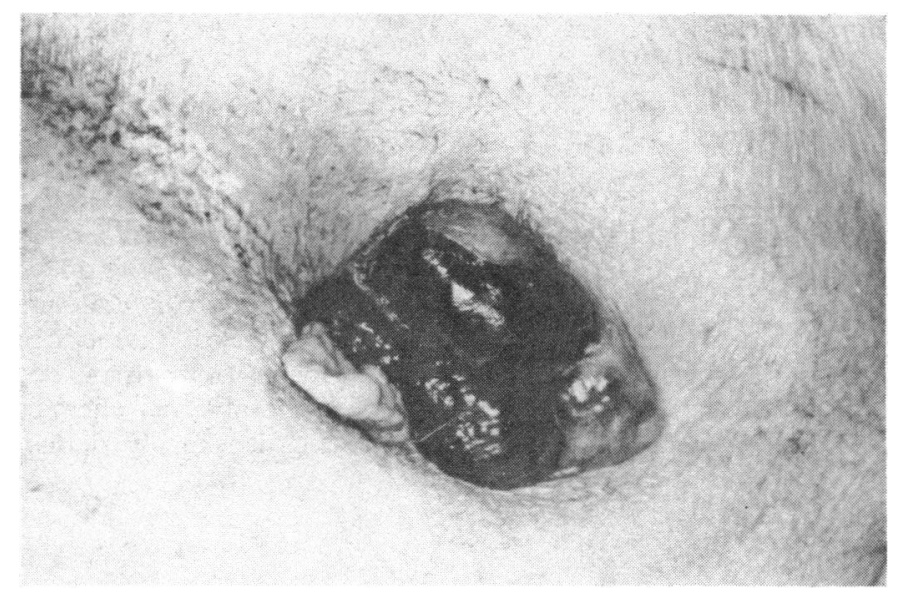

FIG. 3-Third degree haemorrhoids in 70-year-old man, showing the gangreous stage seven days after cryosurgery. 
patches by the fourth day. By the fifth or sixth day the whole haemorrhoidal area is pale, and black gangrenous areas appear on the tip. Gangrene is usually complete between seven and nine days postoperatively (fig. 3). Thereafter the haemorrhoid begins to disintegrate and comes away completely by about the 18th day, leaving a normal looking anus (fig. 4). A profuse and offensive serous discharge begins within the first 12 hours after freezing, which is maximal at about the fifth day, and then gradually diminishes.

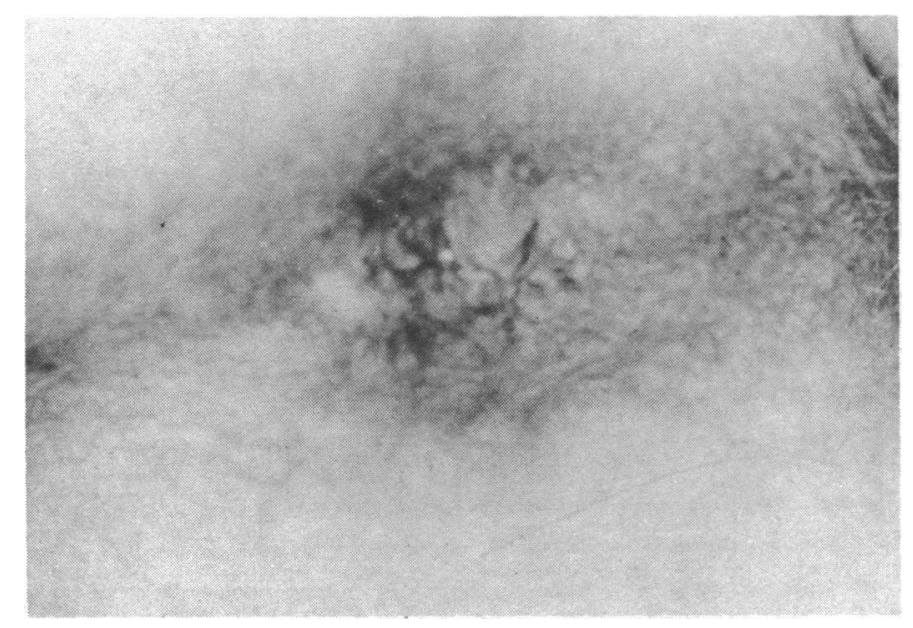

FIG. 4-Same patient as in figs. 1 and 215 months after cryosurgery. There is no evidence of haemorrhoids or anal stenosis.

\section{Results}

\section{POSTOPERATIVE PERIOD}

Pain was minimal as no patient needed more than mild analgesics, and there was no pyrexia. In one case there was slight bleeding because the probe was detached before rewarming, tearing the mucosa. Two patients were returned to hospital by their general practitioners who were alarmed by the gangrenous appearance of the anus, and two of the earlier patients required further cryosurgery at three weeks and five weeks because of inadequate freezing of the haemorrhoids.

\section{SIX-MONTH FOLLOW-UP}

Six months after freezing no patient had prolapse, discharge, pain, or bleeding, apart from one who developed a first degree haemorrhoid which responded to injection. There was no case of incontinence or stricture. Seventeen patients had remaining skin tags, and seven of these complained of occasional irritation.

\section{Discussion}

Recent advances in cryogenic techniques have made it possible to freeze living human tissue in many parts of the body. Tissue, once frozen solid, undergoes necrosis, partly due to thrombosis of the microcirculation.' Autolysis and sloughing subsequently occur within three to five weeks. Tissue destroyed by freezing differs in several respects from tissue destroyed by other means such as diathermy or chemical necrosis. The area destroyed by freezing is sharply demar- cated from the surrounding normal tissue and the boundary layer of damaged cells may be only one or two cells thick. Thrombosis of the micro vessels occurs in frozen tissue, and reactionary and secondary haemorrhage is rare. With standardized techniques the area of cryonecrosis is reproducible. ${ }^{2}$ Freezing produces permanent local anaesthesia in the frozen tissue. The inflammatory response of the body to frozen tissue is minimal, and healing occurs with minimal scarring.

The well-tried treatment of prolapsing haemorrhoids relies on excising the haemorrhoids surgically or destroying them with cautery or pressure, and relieving spasm by anal dilatation or sphincterotomy. These methods provide generally acceptable final results, but progress to these results is often marred for the patient by excessive pain. This has led to the development of procedures designed to lessen the pain. ${ }^{3} \mathrm{Re}-$ cently Lord's procedure of anal dilatation has come into vogue but probably carries too high a failure rate in third degree haemorrhoids to be generally acceptable. ${ }^{4}$

Cryodestruction of the haemorrhoidal tissue is an attractive method and our experience with this technique is in accordance with that of Lewis. ${ }^{5}$ The procedure is painless, general anaesthesia is unnecessary, the area of tissue destruction is precisely demarcated, and complications such as bleeding, sepsis, and incontinence, are few. It has the great drawback of very profuse discharge for up to a week after freezing, which is often offensive and requires frequent changes of dressing or sanitary towels. The classical operation of excision and ligation, however, often requires dressings for a similar period. Our patients have found the discharge acceptable when it was previously explained to them and have been happy to exchange it for a painless convalescence. Many of our patients with third degree haemorrhoids had a profuse discharge before operation. Another disadvantage is that complete removal of the necrotic slough may take up to five weeks and during this period the appearance of the anal area may be alarming.

Two patients in this series had had previous haemorrhoidectomy by the classical method and were in no doubt which procedure they preferred. Two in the earlier part of the series required further cryotherapy as we had not totally destroyed the haemorrhoidal tissue on the first occasion. Both acquiesced to the second procedure, again without anaesthesia, one month after the original operation.

While the immediate results so far have been excellent, there is the possibility of late stricture formation. Though this has not occurred in the one or two patients in this series who have been followed up for 18 months, late stricture formation is a possibility-as we have found in some of our palliative procedures for recurrent neoplasia - and we believe that great care is necessary to preserve the mucocutaneous bridges between the pile areas.

Our thanks are due to the research committee of the South West Regional Hospital Board for a contribution towards the purchase of a nitrogen probe; to Messrs. Keelers Ltd., and Messrs. Spembley Ltd. for the loan of cryosurgical equipment.

\section{References}

1 Fraser, Sir James, and Gill, W., British Fournal of Surgery, 1967, 54,

2 Cooper, I. S., fournal of the American Medical Association, 1972, 181,600 .

3 Parks, A. G., Guy's Hospital Reports, 1955, 104, 135.

4 Chant, A. D. B., May, A., and Wilken, B. J., Lancet, 1972, 2, 398.

5 Lewis, M. I., de la Cruz, Teofilio, Gazzaniga, D. A., and Bail, T., Diseases of the Colon and Rectum, 1969, 12, 371 . 